\title{
The Kinetic Model for Decolourization of Commercial Direct Blue 2 Azo Dye Aqueous Solution by the Fenton Process and the Effect of Inorganic Salts
}

\author{
Hasan F. Al-Rubai*, Ahmed K. Hassan* and Bahaa M. Altahir**† \\ *Environment and Water Directorate, Ministry of Science and Technology, Baghdad, Iraq \\ **Department of Biology, University of Baghdad, Baghdad, 10071, Iraq \\ †Corresponding author: Bahaa M. Altahir; baha782004@gmail.com
}

\author{
Nat. Env. \& Poll. Tech. \\ Website: www.neptjournal.com \\ Received: 18-11-2019 \\ Revised: $29-12-2019$ \\ Accepted: 16-01-2020 \\ Key Words: \\ Azo dye \\ Degradation \\ Fenton process \\ Adsorption kinetics
}

\begin{abstract}
The study of Fenton's oxidation and degradation of Direct Blue 2 (DB2) as the commercial azo dye in synthetic aqueous solution has been accomplished. The optimum oxidative degradation reaction conditions were achieved as follows: $\mathrm{pH}=3.50,\left[\mathrm{H}_{2} \mathrm{O}_{2}\right]=1.1 \times 10^{-3} \mathrm{M},\left[\mathrm{Fe}^{2+}\right]=1.0 \times 10^{-4} \mathrm{M}$ for $[\mathrm{DB} 2]=$ $1.0 \times 10^{-4} \mathrm{M}$. Under optimal conditions, $80 \%$ of decolouration efficiency was carried out within 15 min of reaction. An engagement between the kinetics of the colour removal rates $\left(\ln k_{2}\right)$ versus $L_{\text {azo bond }}$ was carried out at the different $\mathrm{pH}$ levels. The colour removal rate was increased with decreasing of $L_{\text {azo }}$ bond, in the order of $\mathrm{pH}: 3.5>5.0>2.5$. The second-order kinetic model provided the best correlation of the data. Effects of various inorganic anions (such as $\mathrm{Cl}^{-}, \mathrm{SO}_{4}^{2-}, \mathrm{CO}_{3}^{2-}$, etc.) was studied to enhance the oxidation efficiency of Fenton reaction. Advanced oxidation technologies were developed in this study especially with dealing with contaminated textile wastewater over the use of chemical treatment.
\end{abstract}

\section{INTRODUCTION}

The textile industry is a major source of outflowing industrial wastewater due to more exhaustion of water during process operations. This industrial wastewater contains chemicals such as alkalis, acids, dyes, surfactants and matter high in biochemical oxygen demand (Razzak \& Hossain 2016). As the textile industry uses more water than any other industry globally, virtually all wastewater discharged is highly polluted. Water consumption of an average-sized textile mill about 50 gals per kg of fabric manufactured daily (Luo et al. 2016). The most plentiful of these compounds are azo dyes, which exemplify $70 \%$ of the world dye product. Large volumes of industrial wastewater with high scales of azo dyes (about 250 $\mathrm{mg} . \mathrm{L}^{-1}$ ) are every day vacuous by many industries around the world in the surface water. The stability and complexity of the dye structure make it more difficult to degrade when it is present in the textile wastewater (Garcia-Segura \& Brillas 2016). Therefore, the mineralization of dyes generated by the textile industry is the main challenge and environmental concern (Holkar et al. 2016). There are several methods currently used to remove wastewater contamination in the fabric, but they are not universally applicable and are not cost-effective for all dyes (Nidheesh et al. 2013). In the last years, the problem of a high toxic level of wastewater has been tried by Advanced Oxidation Processes (AOPs) (Sharma et al. 2018). AOPs are based on the in-situ generation of hydroxyl radical $\left(\mathrm{HO}^{\circ}, \mathrm{E}^{\circ}\left(\mathrm{HO}^{\circ} / \mathrm{H}_{2} \mathrm{O}\right)=2.80 \mathrm{~V}\right)($ Dewil et al. 2017). The Fenton system is one of the most used techniques to degrade different organic pollutants such as azo-dyes by hydroxyl free radical generated from the hydrogen peroxide molecules reduction with $\mathrm{Fe}^{2+}$ ions at acidic $\mathrm{pH}$ (Jin et al. 2017).

$$
\begin{gathered}
\mathrm{Fe}^{2+}+\mathrm{H}_{2} \mathrm{O}_{2} \rightarrow \mathrm{Fe}^{3+}+\mathrm{HO}^{-}+\mathrm{HO}^{-} \\
\mathrm{Fe}^{3+}+\mathrm{H}_{2} \mathrm{O}_{2} \rightarrow \mathrm{Fe}(\mathrm{OOH})^{2+}+\mathrm{H}^{+} \\
\mathrm{Fe}(\mathrm{OOH})^{2+} \rightarrow \mathrm{Fe}^{2+}+\mathrm{HO}_{2}^{\cdot}
\end{gathered}
$$

In Fenton oxidation process, hydroxyl free radical prefer to attack the azo bond $(-\mathrm{N}=\mathrm{N}-)$ of the dye molecule by cleaving it to produce aromatic amines and inorganic ions such as $\mathrm{NH}_{4}^{+}$(Trovó et al. 2016). For the treatment of industrial textile wastewater containing dyes; the AOPs are effective techniques for degradation of aromatic compounds consequent to the electrophilic aromatic exchange of $\mathrm{HO}^{\circ}$ which then leads to open the aromatic ring (Mousset et al. 2014). The goal of the other treatment is reducing the chemical oxygen demand of the industrial textile wastewater. Typically, these two targets require various chemical reagents like $\mathrm{H}_{2} \mathrm{O}_{2}$ and $\mathrm{Fe}^{2+}$ coincide to either azo bond or chemical oxygen demand loadings (Dehghani et al. 2016). This manuscript reports the colour removal or COD removal kinetics of the DB 2 which contains diazo bond, by Fenton oxidation process. The goals of this study were: (1) to determine the best molar ratio of 
$\mathrm{H}_{2} \mathrm{O}_{2} / \mathrm{Fe}^{2+}$ through Fenton oxidation process of DB 2 at optimum $\mathrm{pH}$ according to the colour removal kinetics with constant $\mathrm{Fe}^{2+}$ and variable $\mathrm{H}_{2} \mathrm{O}_{2}$; (2) at the optimum conditions, estimation of the effects of either azo bond loading factor $\left(L_{\text {azobond }}\right)$ or COD loading factor $\left(L_{\mathrm{COD}}\right)$ at different $\mathrm{pH}$ values in relation to the colour removal kinetic classify and COD removal of DB2 by Fenton oxidation process; (3) at optimum conditions on degradation of DB2, study the effect of the inorganic anions such as sulphate, carbonate chloride and bicarbonate

\section{MATERIALS AND METHODS}

\section{Chemicals}

Direct Blue 2 (DB2) (Ciba Specialty Chemicals Inc). $\mathrm{H}_{2} \mathrm{O}_{2}$ (30\%W/W), $\mathrm{Na}_{2} \mathrm{SO}_{3}$ and $\mathrm{FeSO}_{4} \cdot 7 \mathrm{H}_{2} \mathrm{O}$ were obtained from Merck and $\mathrm{BDH}$. $\mathrm{NaOH}(99 \%)$ and $\mathrm{H}_{2} \mathrm{SO}_{4}(99 \%)$ were used to adjust the $\mathrm{pH}$ which was purchased from Appli Chem $(\mathrm{GmbH})$. To estimate the concentration of hydrogen peroxide, a solution of ammonium metavanadate $\mathrm{NH}_{4} \mathrm{VO}_{3}$ (BDH) was prepared. Its molar concentration was $0.062 \mathrm{M}$ dissolved in sulfuric acid, with a concentration of $0.058 \mathrm{M}$. $\mathrm{KCl}(99 \%), \mathrm{NaCl}(99 \%), \mathrm{Na}_{2} \mathrm{CO}_{3}(99.0 \%), \mathrm{NaHCO}_{3}(98 \%)$, $\mathrm{Na}_{2} \mathrm{SO}_{4}(99 \%)$ and $\mathrm{K}_{2} \mathrm{SO}_{4}(99 \%)$ were obtained from Fluka. All solutions were prepared with distilled water. The main characteristics and chemical structure of DB 2 dye are as shown in Table 1 and Fig. 1.

\section{Experimental Procedure}

The colour removal of the azo dye DB 2 solutions was followed quantitatively by measuring the decrease in absorbance at $\triangle \max =570 \mathrm{~nm}$ using (UV/VIS, Model SP-3000 OPTIMA) spectrophotometer. The chemical oxygen demand (COD) was determined by the method described in EPA method
410.4 (Luo et al. 2016, Razzak \& Hossain 2016). $\mathrm{H}_{2} \mathrm{O}_{2}$ was quantified spectrophotometrically as described by Nogueira (Nogueira et al. 2005). The degradation of DB 2 was carried out by the Fenton process using a batch reactor (total volume of $1 \mathrm{~L}$ ) under constant agitation with a magnetic stirrer and room temperature ranged from $35 \pm 2{ }^{\circ} \mathrm{C}$. The experiments were conducted as the following:

1. To determine the effect of the primary concentration of $\mathrm{H}_{2} \mathrm{O}_{2}\left(0.22 \times 10^{-4}\right.$ to $\left.4.4 \times 10^{-3} \mathrm{M}\right)$ on the removal kinetics of DB $2\left(1 \times 10^{-4} \mathrm{M}\right)$. The experiments were conducted with a constant concentration of iron ions (1 $\left.\times 10^{-4} \mathrm{M}\right)$ and $\mathrm{pH}$ 3.5. A desired amount of $\mathrm{FeSO}_{4} \cdot 7 \mathrm{H}_{2} \mathrm{O}$ was added to each experiment. Either $1 \mathrm{M} \mathrm{H}_{2} \mathrm{SO}_{4}$ or $1 \mathrm{M} \mathrm{NaOH}$ was used to adjust the $\mathrm{pH}$ at the specified value, the proper amount of $\mathrm{H}_{2} \mathrm{O}_{2}$ was added to each batch reactor. To estimate the dye decolourization, 10 $\mathrm{mL}$ of sample was immediately analysed at $1,3,5,7$, $10,15,20,30,45$ and $60 \mathrm{~min}$.

2. For this step of oxidation, the effect of $\left[\mathrm{H}_{2} \mathrm{O}_{2}\right]$ was in the range of $1.0 \times 10^{-5}$ to $2.5 \times 10^{-4} \mathrm{M}$, the stock solution of $\left[\mathrm{H}_{2} \mathrm{O}_{2}\right]$ was $1.1 \times 10^{-3} \mathrm{M}$ and $\mathrm{pH}$ of the dye solution was constant at 3.5 on decolourization rate of [DB 2] = $1.0 \times 10^{-4} \mathrm{M}$.

3. The most favourable molar ratio $\mathrm{H}_{2} \mathrm{O}_{2} / \mathrm{Fe}^{2+}$ was experimentally determined by changing either $\mathrm{H}_{2} \mathrm{O}_{2}$ or $\mathrm{Fe}^{2+}$ concentrations as described in the first and second steps. In the literature review, $\mathrm{H}_{2} \mathrm{O}_{2}$ and $\mathrm{Fe}^{2+}$ doses were determined by carrying out several experiments at different ratios of $\mathrm{H}_{2} \mathrm{O}_{2}$ and $\mathrm{Fe}^{2+}$ doses (Kehinde \& Abdul Aziz 2014, Garcia-Segura \& Brillas 2016, Luo et al. 2016).

4. Experiments were achieved at three $\mathrm{pH}$ values $(2.5,3.5$ and 5.0) and different $L_{\text {azobond }}$ for the Fenton oxidation process. The colour removal (decolourization) kinetic

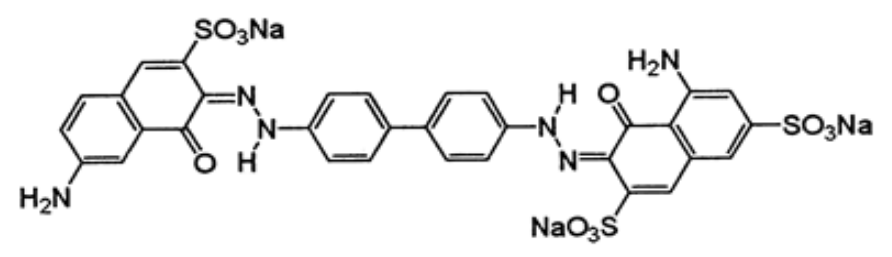

Fig. 1: Chemical structure of DB2.

Table 1: Characteristics of DB 2.

\begin{tabular}{|ll|}
\hline Properties & Value \\
\hline Chemical formula & $\mathrm{C}_{32} \mathrm{H}_{12} \mathrm{~N}_{6} \mathrm{Na}_{3} \mathrm{O}_{11} \mathrm{~S}_{3}$ \\
Molar Mass & $831 \mathrm{~g} / \mathrm{mol}$ \\
Functional group & Diazo \\
Color, $\lambda \max (\mathrm{nm})$ & Deep Purple, 570 \\
\hline
\end{tabular}


of $1.0 \times 10^{-4} \mathrm{M}$ of DB 2, was studied at different $L_{\text {azo bond }}$ (1.0, 0.75, 0.5 and 0.25$)$ which are equivalent to $\mathrm{H}_{2} \mathrm{O}_{2}$ concentrations $\left(2.0 \times 10^{-4}, 2.7 \times 10^{-4}, 4.0 \times 10^{-4}\right.$ and 8.0 $\times 10^{-4} \mathrm{M}$ ), respectively for the demolition of azo group bond at a constant $\mathrm{H}_{2} \mathrm{O}_{2} / \mathrm{Fe}^{2+}$ molar ratio of 11 .

5. The COD removal of DB 2, was studied at different $L_{\text {COD }}(1.0,0.75,0.5$, and 0.25$)$ at $\mathrm{H}_{2} \mathrm{O}_{2} / \mathrm{Fe}^{2+}$ molar ratio equal to 11. Different $\mathrm{H}_{2} \mathrm{O}_{2}$ concentrations: $1.4 \times 10^{-2}$, $1.9 \times 10^{-2}, 2.8 \times 10^{-2}$ and $5.6 \times 10^{-2} \mathrm{M}$ equivalent to $L_{\mathrm{COD}}(1.0,0.75,0.5$, and 0.25$)$ were used for the COD removal, for the reason that the empirical COD concentration gained at $1.0 \times 10^{-4} \mathrm{M}$ DB 2 solution was 224 $\mathrm{mg} \mathrm{O}_{2} \mathrm{~L}^{-1}\left(\mathrm{COD}=7.0 \times 10^{-3} \mathrm{M}\right)$.

6. The effect of $1.0 \%$ of inorganic salts on decolourization of DB 2 at $\left(1.0 \times 10^{-4} \mathrm{M}\right)$ was investigated. $10 \mathrm{~g}$ of inorganic salt was added to $1 \mathrm{~L}$ batch reactor for each experiment.

7. To ensure the removal of residual hydrogen peroxide $\mathrm{H}_{2} \mathrm{O}_{2}, 100 \mu \mathrm{L}$ of $1.0 \mathrm{M}$ sodium sulphate $\mathrm{Na}_{2} \mathrm{SO}_{3}$ solution, was added to all samples before the analysis by UV-Vis. Thus, the residual of $\mathrm{H}_{2} \mathrm{O}_{2}$ was destroyed and Fenton reactions were stopped (Holkar et al. 2016). While, to measure the COD concentration in the treated water, the interference from residual $\mathrm{H}_{2} \mathrm{O}_{2}$ was removed by addition of $\mathrm{Na}_{2} \mathrm{CO}_{3}(20 \mathrm{~g} / \mathrm{L})$ and placed in a water bath at $90^{\circ} \mathrm{C}$ for $60 \mathrm{~min}$ ( $\mathrm{Wu}$ and Englehardt 2012, Nidheesh et al. 2013).

\section{RESULTS AND DISCUSSION}

Results presented here are based on the batch system of degradation of DB 2 by Fenton oxidation. The parameters for colour removal (decolourization) efficiencies such as loading azo bond factor $\left(L_{\text {azo bond }}\right)$ or COD loading factor
$\left(L_{\mathrm{COD}}\right)$ were studied; which are defined by Eqs. 4 and 5 , respectively (Trovó et al. 2016, Sharma et al. 2018). In oxidation processes using the Fenton's reagent, the amount of oxygen $\mathrm{O}_{2}$ available in $\mathrm{H}_{2} \mathrm{O}_{2}$ must be measured to produce free hydroxyl radicals $\mathrm{HO}^{\circ}$ responsible for the breakdown of the azo bond and the intermediate organic compounds (Sharma et al. 2018). Therefore, the dosage of $\mathrm{H}_{2} \mathrm{O}_{2}$ required should be based on the initial $L_{\text {azo bond }}, L_{\mathrm{COD}}$ of DB 2, and $\mathrm{O}_{2}$ supplied by $\mathrm{H}_{2} \mathrm{O}_{2}$, respectively.

$$
\begin{aligned}
L_{\text {azo bond }} & =\left\{[\mathrm{DB} 2]_{\text {initial }}(\mathrm{M})\right\} / \mathrm{O}_{2 \text { available }}(\mathrm{M}) \\
L_{\mathrm{COD}} & =\left\{\mathrm{COD}_{\text {initial }}(\mathrm{M})\right\} / \mathrm{O}_{2 \text { available }}(\mathrm{M})
\end{aligned}
$$

Where, DB2 $2_{\text {initial }}$ and $\mathrm{COD}_{\text {initial }}$ are the initial concentration and the chemical oxygen demand of DB 2 dye, respectively. Dye decolourization efficiency was calculated as follows:

$(\%)$ Dye colour removal efficiency $=\left(1-\mathrm{C}_{\mathrm{t}} / \mathrm{C}_{0}\right) \times 100$

Where, $\mathrm{C}_{\mathrm{t}}$ and $\mathrm{C}_{0}\left(\mathrm{~mol} . \mathrm{L}^{-1}\right)$ are the concentrations of DB 2 dye at reaction time $t$ and 0 , respectively. The chemical oxygen demand removal percentage was calculated as follows:

$$
(\%) \mathrm{COD} \text { removal }=\left(1-\mathrm{COD}_{\mathrm{t}} / \mathrm{COD}_{0}\right) \times 100
$$

Where, $\mathrm{COD}_{\mathrm{t}}$ and $\mathrm{COD}_{0}$ are the chemical oxygen demand of DB 2 dye at reaction time $t$ and 0 , respectively.

\section{Effect of the $\mathrm{H}_{2} \mathrm{O}_{2}$ Dose on the Removal of DB 2}

In the Fenton process, hydrogen peroxide plays an essential role in contaminant removal efficiency. Therefore, it was necessary to find the optimum hydrogen peroxide concentrations. The decolourization of $1.0 \times 10^{-4} \mathrm{MDB} 2$ was evaluated in the range of $\left(0.22 \times 10^{-4}\right.$ and $\left.4.5 \times 10^{-3} \mathrm{M}\right) \mathrm{H}_{2} \mathrm{O}_{2}$ and constant amount of ferrous iron $\left(1 \times 10^{-4} \mathrm{M}\right.$ or $\left.5.6 \mathrm{mg} / \mathrm{L}\right)$ to find the optimal oxidant dosage. The effect of hydrogen peroxide

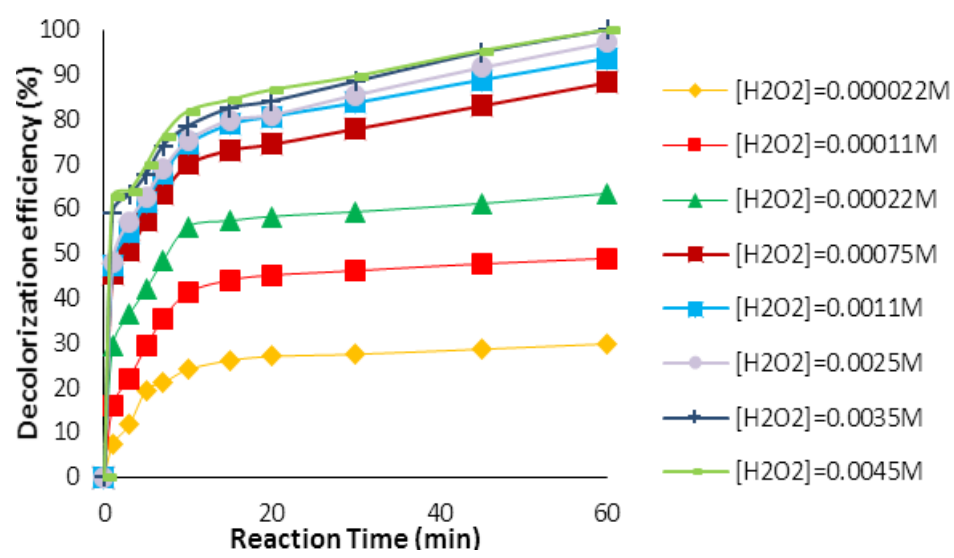

Fig. 2: DB 2 reaction time effect on decolourization of dye by Fenton oxidation at various $\mathrm{H}_{2} \mathrm{O}_{2}$ doses. Experimental conditions: $[\mathrm{DB} 2]=1.0 \times 10^{-4} \mathrm{M},\left[\mathrm{Fe}^{2+}\right]=1.0 \times 10^{-4} \mathrm{M}$ and $\mathrm{pH}=3.5$. 
concentration and reaction time are shown in Fig. 2. At the concentration of $0.22 \times 10^{-4} \mathrm{M}$, the colour removal of DB 2 was $24.0 \%$ after $10 \mathrm{~min}$ of the reaction. However, the increment of peroxide dosage till $1.1 \times 10^{-3} \mathrm{M}$, a colour removal was reached at a higher level of $74.0 \%$. The concentration of $1.1 \times$ $10^{-3} \mathrm{M} \mathrm{H}_{2} \mathrm{O}_{2}$ was selected as the best concentration and used in all experiments to estimate the effects of $\mathrm{Fe}^{2+}$ concentration on DB 2. At $\mathrm{H}_{2} \mathrm{O}_{2}$ concentration of higher than $1.1 \times 10^{-3} \mathrm{M}$, the decolourization efficiency of dye solution showed little considerable efficiency, which may be due to the reaction of hydroxyl radicals with $\mathrm{H}_{2} \mathrm{O}_{2}$, and scavenging of $\mathrm{HO}^{\circ}$ radicals takes place as shown in Eq. 8 (Liu et al. 2017).

$$
\mathrm{HO}^{\bullet}+\mathrm{H}_{2} \mathrm{O}_{2} \rightarrow \mathrm{H}_{2} \mathrm{O}+\mathrm{HO}_{2}^{\cdot} k_{1}=2.7 \times 10^{7} \mathrm{M}^{-1} . \mathrm{S}^{-1} .
$$

\section{The kinetics of influence of $\mathrm{H}_{2} \mathrm{O}_{2}$ concentration on DB 2 decolourization}

Because of different side reactions occurring at the same time, the kinetic study of Fenton oxidation is highly complicated. Two models of kinetic studies were experimented to achieve the kinetics parameters. The first and second-order reaction, have been tested to fit the experimental data obtained from the colour removal experiments. The correlation coefficient
$\left(\mathrm{R}^{2}\right)$ was used in the comparison of the two models. The data of Table 2 illustrate that the first-order model was not useful enough for proper parameter selection may due to the low correlation parameters, while the second-order reaction was much better. The results illustrated that the colour removal kinetics of DB 2 followed the second-order model very well.

Fig. 3 shows that the DB 2 colour removal kinetic rates at constant iron ions of $1.0 \times 10^{-4} \mathrm{M}$ increase with the $\mathrm{H}_{2} \mathrm{O}_{2}$ concentration in two steps. The first step was at the small amount of $\mathrm{H}_{2} \mathrm{O}_{2}$ ranged $0.22 \times 10^{-4}$ to $1.1 \times 10^{-3} \mathrm{M}$, the DB 2 colour removal kinetics increased slowly with a rate constant, $\mathrm{k}=2 \times 10^{6}\left[\mathrm{H}_{2} \mathrm{O}_{2}\right]+416.97$ and with higher correlation coefficient value of $\mathrm{R}^{2}=0.9715$. The second step was at the concentration of $\mathrm{H}_{2} \mathrm{O}_{2}$ was increased from $1.1 \times 10^{-3}$ to 4.5 $\times 10^{-3} \mathrm{M}$, DB 2 colour removal kinetics was increased, and a rate constant $\mathrm{K}=372437\left[\mathrm{H}_{2} \mathrm{O}_{2}\right]+2014.7$ and correlation coefficient $\mathrm{R}^{2}$ was decreased to a value of 0.8561 (Fig. 3). The positive effect of DB 2 colour removal kinetics values was observed with a high concentration of $\mathrm{H}_{2} \mathrm{O}_{2}$ may be due to the high production of hydroxyl free radical. When $\mathrm{H}_{2} \mathrm{O}_{2}$ concentration was larger than $1.1 \times 10^{-3} \mathrm{M}$ (Fig. 3), the DB 2 colour removal kinetics was linearly increased, the

Table 2: First and second orders kinetic parameters and correlation coefficients for each $\mathrm{H}_{2} \mathrm{O}_{2}$ concentration. Experimental conditions: $\left[\mathrm{Fe}^{2+}\right]=$ $1.0 \times 10^{-4} \mathrm{M}, \mathrm{pH}=3.5$ and $[\mathrm{DB} 2]=1.0 \times 10^{-4} \mathrm{M}$.

\begin{tabular}{|llllll|}
\hline$\left[\mathrm{H}_{2} \mathrm{O}_{2}\right](\mathrm{M})$ & $\mathrm{H}_{2} \mathrm{O}_{2} / \mathrm{Fe}^{+2}$ & \multicolumn{2}{l|}{ First-order } & \multicolumn{2}{l|}{ Second-order } \\
\cline { 3 - 6 } & & $\mathrm{K}_{1}\left(\mathrm{~min}^{-1}\right)$ & $\mathrm{R}^{2}$ & $\mathrm{~K}_{2}\left(\mathrm{M}^{-1} . \min ^{-1}\right)$ & 3890 \\
$\mathrm{R}^{2}$ \\
\hline $4.5 \times 10^{-3}$ & 45 & 0.1355 & 0.7649 & 3171 & 0.9233 \\
$2.5 \times 10^{-3}$ & 35 & 0.1227 & 0.7472 & 2714 & 0.9124 \\
$2.5 \times 10^{-3}$ & 25 & 0.1171 & 0.8322 & 2604 & 0.9547 \\
$1.1 \times 10^{-3}$ & 11 & 0.1148 & 0.8418 & 2035 & 0.9567 \\
$7.5 \times 10^{-4}$ & 7.5 & 0.0994 & 0.8186 & 1128 & 0.9343 \\
$2.2 \times 10^{-4}$ & 2.2 & 0.0704 & 0.8799 & 356 & 0.9332 \\
$1.1 \times 10^{-4}$ & 1.1 & 0.0737 & 0.8786 & 312 & 0.9323 \\
$0.22 \times 10^{-4}$ & 0.22 & 0.0268 & 0.9168 & \\
\hline
\end{tabular}

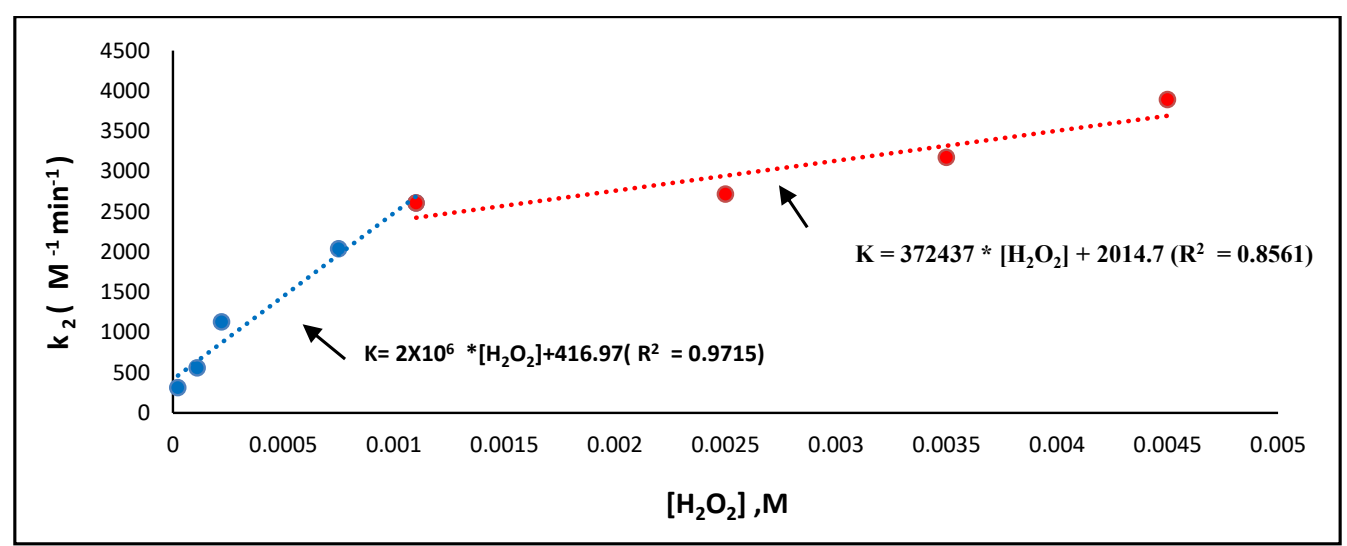

Fig. 3: Correlations among the second order kinetic constants versus $\mathrm{H}_{2} \mathrm{O}_{2}$ used, obtained during DB 2 decolourization by Fenton process. Initial conditions: $\left[\mathrm{Fe}^{2+}\right]=1 \times 10^{-4} \mathrm{M}, \mathrm{pH}=3.5$ and $[\mathrm{DB} 2]=1.0 \times 10^{-4} \mathrm{M}$. 
regression coefficient value was decreased at the same time. It suggests that the overdosed $\mathrm{H}_{2} \mathrm{O}_{2}$ was scavenging hydroxyl free radicals excessively (Eq. 8). Consequently, $1.1 \times 10^{-3}$ $\mathrm{M} \mathrm{H}_{2} \mathrm{O}_{2}$ was selected as the optimum concentration on DB 2 colour removal kinetics.

\section{Effect of $\mathrm{Fe}^{2+}$ Doses on the Removal of DB 2}

The influence of $\mathrm{Fe}^{2+}$ stimulation on the removal of DB 2 was examined using the different $\mathrm{Fe}^{2+}$ concentrations. The $\left[\mathrm{Fe}^{2+}\right]$ were in range of $1.0 \times 10^{-5}$ to $2.5 \times 10^{-4} \mathrm{M}$ with constant $\mathrm{H}_{2} \mathrm{O}_{2}$ concentration of $1.1 \times 10^{-3} \mathrm{M}$. Increase of the concentration of $\left[\mathrm{Fe}^{2+}\right]$ from $1.0 \times 10^{-5}$ to $1.0 \times 10^{-4} \mathrm{M}$ had the positive effect on the removal rate for DB 2 (Fig. 4). The colour removal was increased from $22.0 \%$ to $74.0 \%$ at $10 \mathrm{~min}$ of the reaction, that effect may be due to the activity of $\mathrm{Fe}^{2+}$ in initiating the degradation of $\mathrm{H}_{2} \mathrm{O}_{2}$ to generate hydroxyl free radicals as a part of Fenton process. These radicals can reacted with DB 2 instantly, that lead to DB 2 degradation (Lucas \& Peres 2006). When the concentration of $\mathrm{Fe}^{2+}$ was increased to higher than $1.0 \times 10^{-4} \mathrm{M}$, a slight increase in the decomposition rate may have occurred and that improved the function of $\mathrm{Fe}^{2+}$ as a scavenger of $\mathrm{HO}^{*}$ (Eq. 9). Hence, the optimum $\mathrm{Fe}^{2+}$ concentration of the removal of DB 2 was selected as $1.0 \times 10^{-4} \mathrm{M}$.

$\mathrm{Fe}^{2+}+\mathrm{HO}^{\bullet} \otimes \mathrm{Fe}^{3+}+\mathrm{OH}^{-} \quad k_{2}=3 \times 10^{8} \mathrm{M}^{-1} \cdot \mathrm{S}^{-1}$

\section{The Kinetics of Influence of $\mathrm{Fe}^{2+}$ Concentration on DB 2 Colour Removal}

Two kinetic models were studied to estimate the effect of $\mathrm{Fe}^{2+}$ concentrations on the decomposition kinetics of DB 2. Table 3 shows the kinetic parameters of the study. The regression coefficient $\left(\mathrm{R}^{2}\right)$ values of the second-order reaction were higher than the first-order and we concluded that the colour removal kinetics of DB 2 obeys to the second-order kinetics model. The correlation between the second-order kinetics of the DB 2 colour removal and different $\mathrm{Fe}^{2+}$ concentrations (from $1.5 \times 10^{-5}$ to $2.5 \times 10^{-4} \mathrm{M}$ ) are presented in Fig. 5. Fig. 5 elucidates that the DB 2 colour removal kinetic average increase with the increase of $\mathrm{Fe}^{2+}$ in two varied steps as well: (1) At low concentration of $\mathrm{Fe}^{2+}$ ranged from $1.5 \times 10^{-5}$ to $1.0 \times 10^{-4} \mathrm{M}$, the DB 2 colour removal kinetics was increased clearly with a slope of $3.0 \times 10^{7}$. (2) At high concentration of $\mathrm{Fe}^{2+}$ (from $1.5 \times 10^{-4}$ to $2.5 \times 10^{-4} \mathrm{M}$ ), DB 2 colour removal kinetics increased also but the slope $\left(9.0 \times 10^{6}\right)$ was decreased. At low colour removal kinetics in the second step in comparison with the first step, the proposition may lead to that $\mathrm{Fe}^{2+}$ was higher than the need for consumption amount of $\mathrm{HO}^{\bullet}$ (Eq. 10). Thus, the amount of hydroxyl free radicals available to oxidize DB 2 dye became very low. The positive effect of $\mathrm{Fe}^{2+}$ on the DB 2 colour removal kinetics assured that $\mathrm{Fe}^{2+}$ stimulate by fast dissociation of $\mathrm{H}_{2} \mathrm{O}_{2}$ into $\mathrm{HO}^{\circ}$ radicals;

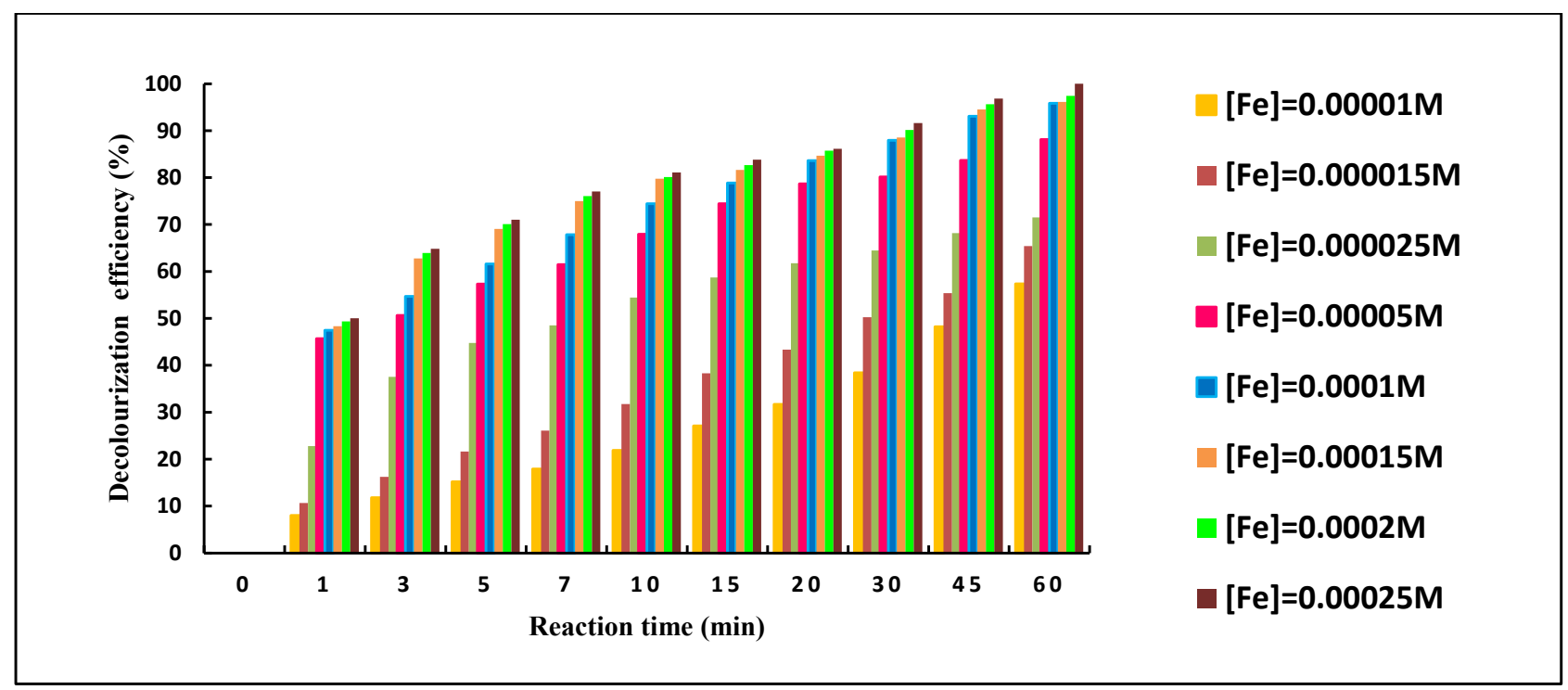

Fig. 4: DB 2 Decolourization by Fenton's reagent oxidation at different $\mathrm{Fe}^{+2}$ concentrations. Experimental conditions: $\left[\mathrm{H}_{2} \mathrm{O}_{2}\right]=1.1 \times 10^{-3} \mathrm{M}, \mathrm{pH}=3.5$ and $[\mathrm{DB} 2]=1.0 \times 10^{-4} \mathrm{M}$. 


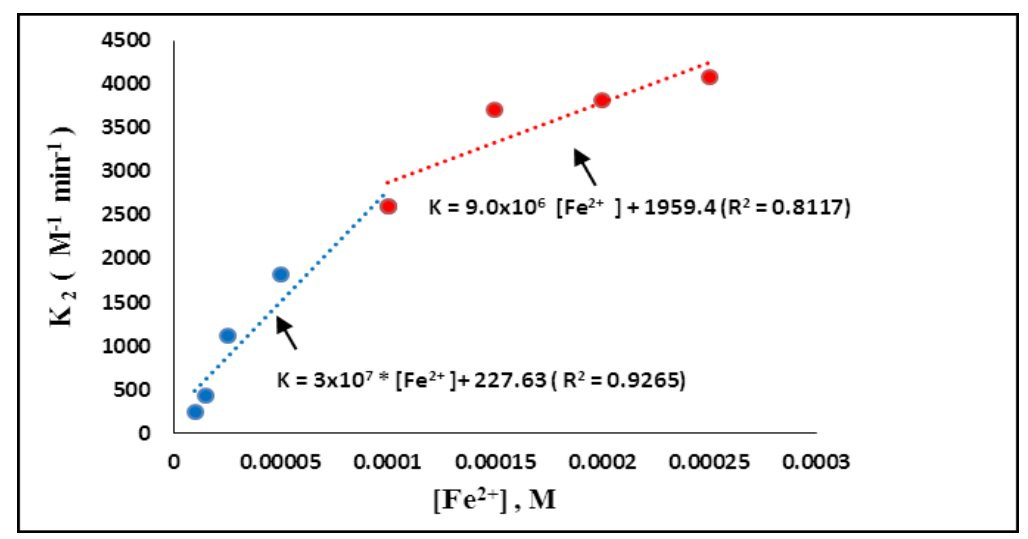

Fig. 5: Correlation between the second-order kinetic constants versus $\mathrm{Fe}^{2+}$ used found during DB 2 decolourization by Fenton process. Primary conditions: $\left[\mathrm{H}_{2} \mathrm{O}_{2}\right]=1.1 \times 10^{-3} \mathrm{M}, \mathrm{pH}=3.5$ and $[\mathrm{DB} 2]=1.0 \times 10^{-4} \mathrm{M}$

Table 3: First and second-order kinetic parameters and regression coefficients for each $\mathrm{Fe}^{2+}$ concentrations. Experimental conditions: $[\mathrm{DB}$ 2] $=$ $1.0 \times 10^{-4} \mathrm{M},\left[\mathrm{H}_{2} \mathrm{O}_{2}\right]=1.1 \times 10^{-3} \mathrm{M}$ and $\mathrm{pH}=3.5$.

\begin{tabular}{|c|c|c|c|c|c|}
\hline \multirow[t]{2}{*}[\mathrm{Fe}^{+2}]{$\quad(\mathrm{M})$} & \multirow[t]{2}{*}{$\mathrm{H}_{2} \mathrm{O}_{2} / \mathrm{Fe}^{2+}$} & \multicolumn{2}{|c|}{ First-order } & \multicolumn{2}{|l|}{ Second-order } \\
\hline & & $\begin{array}{l}\mathrm{K}_{1} \\
\left(\min ^{-1}\right)\end{array}$ & $\mathrm{R}^{2}$ & $\begin{array}{l}\mathrm{K}_{2} \\
\left(\mathrm{M}^{-1} \cdot \mathrm{min}^{-1}\right)\end{array}$ & $\mathrm{R}^{2}$ \\
\hline $1.0 \times 10^{-5}$ & 110 & 0.0223 & 0.9259 & 255 & 0.9446 \\
\hline $1.5 \times 10^{-5}$ & 73 & 0.0353 & 0.9524 & 435 & 0.9733 \\
\hline $2.5 \times 10^{-5}$ & 44 & 0.0719 & 0.8826 & 1126 & 0.9449 \\
\hline $5.0 \times 10^{-5}$ & 22 & 0.0922 & 0.7821 & 1820 & 0.9064 \\
\hline $1.0 \times 10^{-4}$ & 11 & 0.1148 & 0.8418 & 2604 & 0.9567 \\
\hline $1.5 \times 10^{-4}$ & 7.3 & 0.1403 & 0.8541 & 3707 & 0.9765 \\
\hline $2.0 \times 10^{-4}$ & 5.5 & 0.1422 & 0.8443 & 3820 & 0.9724 \\
\hline $2.5 \times 10^{-4}$ & 4.4 & 0.1471 & 0.8489 & 4085 & 0.9764 \\
\hline
\end{tabular}

that may be due to the $\mathrm{Fe}^{2+}$ not capable to oxidize organic molecules. When $\mathrm{Fe}^{2+}$ dose is more than $1.0 \times 10^{-4} \mathrm{M}$ (Fig. 5); the DB 2 colour removal kinetics rate increased linearly with lower intensity by scavenging $\mathrm{HO}^{\circ}$ radicals. Thus, $1.0 \times 10^{-4}$ $\mathrm{M} \mathrm{Fe}^{2+}$ was selected as the optimum concentration.

\section{$\mathrm{H}_{2} \mathrm{O}_{2} / \mathrm{Fe}^{2+}$ Molar Ratio Effect on DB 2 Decolourization Kinetics}

Concentrations of $\mathrm{H}_{2} \mathrm{O}_{2}$ over $\mathrm{Fe}^{2+}$ are important parameters to optimize for the determination of the ratio $\mathrm{H}_{2} \mathrm{O}_{2} / \mathrm{Fe}^{2+}$ to achieve the maximum Decolourization efficiency of DB 2 from aqueous solutions. The ratio has been used in the following experiments. Several studies have reported that the effect of the optimum molar ratio of Fenton reagent $\mathrm{H}_{2} \mathrm{O}_{2} / \mathrm{Fe}^{2+}$ was disparate for colour removal of azo dyes. For a perfect example, the ratio of $\mathrm{H}_{2} \mathrm{O}_{2} / \mathrm{Fe}^{2+}$ was $20: 1$ for C.I. Reactive Blue 4 and C.I. Reactive Red 2 (Agustina and Ang 2012), while the ratio was 40:1 for Reactive Black 5 (Lucas \& Peres 2006, Dewil et al. 2017). These variations likely attributed to different proposed oxidation mechanisms during the Fenton oxidation process of different azo dyes. Table 2 and Table 3 show the results obtained in this study, the optimum concentrations of $\mathrm{H}_{2} \mathrm{O}_{2}$ and $\mathrm{Fe}^{2+}$ were $1.1 \times 10^{-3}$ $\mathrm{M}$ and $1.0 \times 10^{-4} \mathrm{M}$, respectively. Consequently, the experimental optimum $\mathrm{H}_{2} \mathrm{O}_{2} / \mathrm{Fe}^{2+}$ molar ratio of 11 was selected for the next experiments.

\section{Effect of $\mathrm{pH}$ and $L_{\mathrm{azo} \text { bond }}$ on DB 2 Color Removal Kinetics}

The $\mathrm{pH}$ effect on the Decolourization of DB 2 was achieved by a series of experiments conducted at three initial $\mathrm{pH}$ values 2.5, 3.5 and 5 (Fig. 6). The reaction time was 60 min and constant concentration of $\mathrm{H}_{2} \mathrm{O}_{2}=1.1 \times 10^{-3} \mathrm{M}$ and $\mathrm{Fe}^{2+}=1.0 \times 10^{-4} \mathrm{M}$. pH of 2.5 had the negative effect on $\mathrm{HO}^{\circ}$ radical production in the reaction of $\mathrm{H}_{2} \mathrm{O}_{2}$ with $\mathrm{Fe}^{2+} \mathrm{Eq}$. (1), This may be attributed to $\mathrm{HO}^{\circ}$ scavenging by $\mathrm{H}^{+}$ions; which elucidate the decrease of the colour removal efficiency at pH 2.5 (Esteves et al. 2016, Jin et al. 2017). On the other hand, at $\mathrm{pH} 3.5$, the Decolourization efficiency of DB 2 rapidly increased with the increase in $\mathrm{pH}$, at $\mathrm{pH} 3.5$ almost 
$100 \%$ of Decolourization efficiency was achieved (Fig. 6). The main reason is that more $\mathrm{Fe}(\mathrm{OH})^{+}$is formed, which has much higher activity compared to $\mathrm{Fe}^{2+}$ in the Fenton process (Lopez-Alvarez et al. 2012, Trovó et al. 2016). Besides, at higher $\mathrm{pH}(\mathrm{pH} 5)$, the precipitation of ferric hydroxide happen, causing the reduction in the dissolving $\mathrm{Fe}^{3+}$ ions. Aside from, in such circumstances, $\mathrm{H}_{2} \mathrm{O}_{2}$ is less stable, resulting in less $\mathrm{HO}^{\circ}$ radicals formed, decreasing the removal efficiency of Fenton oxidation (Mousset et al. 2014, Jin et al. 2017). Therefore, the $\mathrm{pH} 3.5$ was chosen the optimum $\mathrm{pH}$ of Fenton oxidation process. At molar ratio of $\mathrm{H}_{2} \mathrm{O}_{2} / \mathrm{Fe}^{2+}$ equal to 11 , the effect of four $L_{\text {azo bond }}$ operator values $(0.25,0.5,0.75$, and 1.0) was evaluated.

Table 4 shows four levels of $L_{\text {azo bond }}$ and symbolized well by the second-order kinetic model. The results elucidate the significant difference in DB 2 colour removal rates at every $\mathrm{pH}$ and $L_{\text {azo bond. }}$ The results in Table 4 approved the selection of $\mathrm{pH} 3$ in Decolourization rates of DB 2 dye. The data were in harmony with previous literatures for assessment of the colour removal of Amido black 10B and Terasil Red R (Dehghani et al. 2016). The best DB 2 colour removal rates were found at the smallest $L_{\text {azo bond }}$ factor of 0.25 and higher

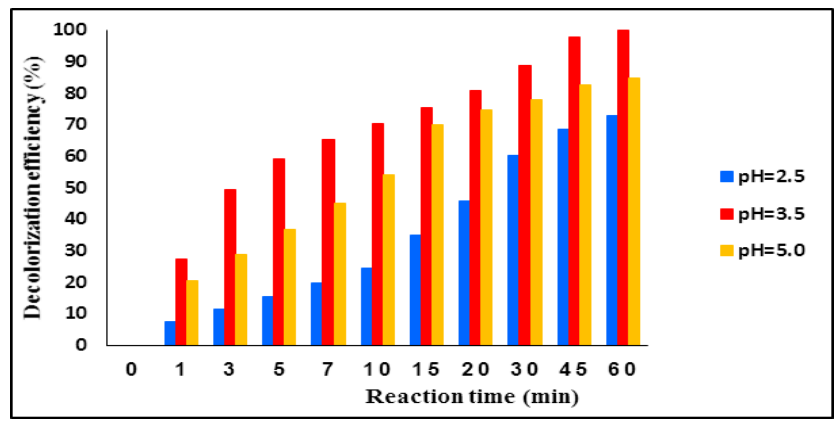

Fig. 6: Effect of $\mathrm{pH}$ on the colour removal efficiency of DB 2 by Fenton process. Experimental conditions; $\left[\mathrm{Fe}^{2+}\right]=1.0 \times 10^{-4} \mathrm{M},\left[\mathrm{H}_{2} \mathrm{O}_{2}\right]=1.1 \times 10^{-3} \mathrm{M}$ and $[\mathrm{DB} 2]=1.0 \times 10^{-4} \mathrm{M}$.

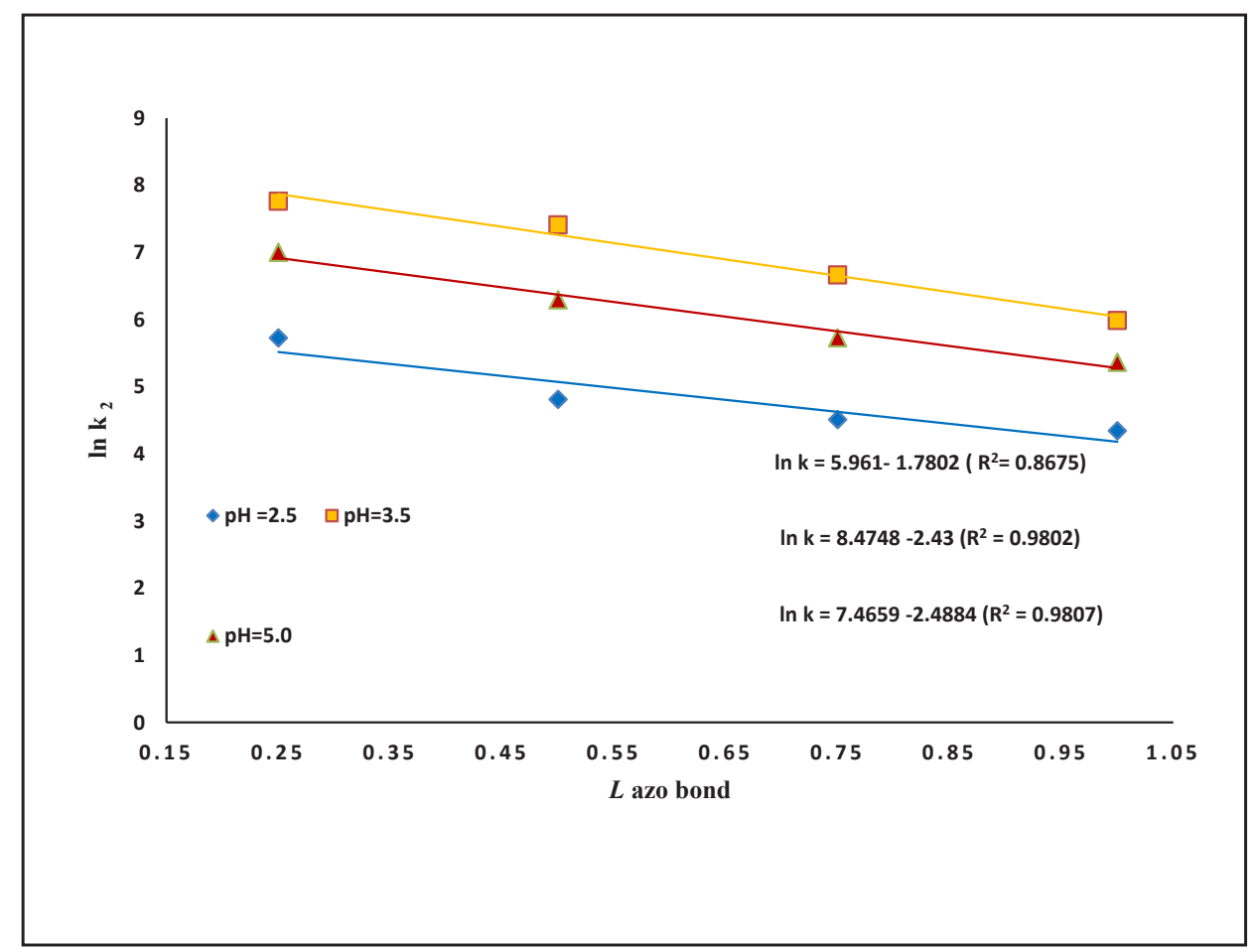

Fig. 7: Correlations between $\ln \mathrm{k}_{2}$ of the colour removal rates versus $L_{\mathrm{azo} \text { bond }}$ at different $\mathrm{pH}$ values obtained during Fenton oxidation of $1.0 \times 10^{-4} \mathrm{M}$ DB 2 . 
Table 4: Second-order kinetic model and regression parameters for every $\mathrm{pH}$ and $L_{\text {azo bond }}$ value during Fenton oxidation of $1.0 \times 10^{-4} \mathrm{M} \mathrm{DB} 2$.

\begin{tabular}{|c|c|c|c|c|}
\hline $\mathrm{pH}$ & $\begin{array}{l}\mathrm{L}_{\text {azo bond }} \\
1.0\end{array}$ & $\begin{array}{l}\mathrm{L}_{\text {azo bond }} \\
0.75\end{array}$ & $\begin{array}{l}\mathrm{L}_{\text {azo bond }} \\
0.5\end{array}$ & $\begin{array}{l}\mathrm{L}_{\text {azo bond }} \\
0.25\end{array}$ \\
\hline 2.5 & $\begin{array}{l}\mathrm{k}_{2}=77 \\
\mathrm{R}^{2}=0.8967\end{array}$ & $\begin{array}{l}\mathrm{k}_{2}=91 \\
\mathrm{R}^{2}=0.970\end{array}$ & $\begin{array}{l}\mathrm{k}_{2}=123 \\
\mathrm{R}^{2}=0.929\end{array}$ & $\begin{array}{l}\mathrm{k}_{2}=307 \\
\mathrm{R}^{2}=0.8675\end{array}$ \\
\hline 3.5 & $\begin{array}{l}\mathrm{k}_{2}=398 \\
\mathrm{R}^{2}=0.9895\end{array}$ & $\begin{array}{l}\mathrm{k}_{2}=784 \\
\mathrm{R}^{2}=0.989\end{array}$ & $\begin{array}{l}\mathrm{k}_{2}=1654 \\
\mathrm{R}^{2}=0.986\end{array}$ & $\begin{array}{l}\mathrm{k}_{2}=2351 \\
\mathrm{R}^{2}=0.98\end{array}$ \\
\hline 5.0 & $\begin{array}{l}\mathrm{k}_{2}=1098 \\
\mathrm{R}^{2}=0.920\end{array}$ & $\begin{array}{l}\mathrm{k}_{2}=542 \\
\mathrm{R}^{2}=0.94\end{array}$ & $\begin{array}{l}\mathrm{k}_{2}=308 \\
\mathrm{R}^{2}=0.933\end{array}$ & $\begin{array}{l}\mathrm{k}_{2}=214 \\
\mathrm{R}^{2}=0.911\end{array}$ \\
\hline
\end{tabular}

$\mathrm{k}_{2}$ values, due to the smaller $L_{\text {azo bond }}$ factor represented a greater amount of $\mathrm{H}_{2} \mathrm{O}_{2}$ concentration per mole of DB 2 and coincides with the larger $\mathrm{O}_{2}$ concentration able to be used for oxidizing the DB 2 dye. Fig. 7 presents a linear relation between the second-order kinetic $\ln \mathrm{k}_{2}$ value and the $L_{\text {azo bond }}$ at each $\mathrm{pH}$ value.

\section{COD Removal of RR120 at Different $L_{\text {COD }}$ Factors}

Although homogeneous catalytic process decolorized the DB 2, the DB 2 azo dye was not completely mineralized. For this reason it is necessary to consider complementary information about the degradation of the organic pollutants (O'Dell 1939, Holkar et al. 2016). Chemical oxygen demand (COD) gives an average measure of the oxidation state of the organic by-products generated during the degradation of DB 2 (Orhon \& Çokgör 1997) . Under the optimal conditions of pH 3.5 and $\mathrm{H}_{2} \mathrm{O}_{2} / \mathrm{Fe}^{2+}$ ratio of 11 , experiments using four varied $L_{\mathrm{COD}}$ values $(0.25,0.5,0.75,1.0)$ were performed to examine the efficiency of Fenton reagent on COD removal kinetics of DB 2 (Fig. 8). The COD removal increases with decreasing $L_{\mathrm{COD}}$ because the hypothetical amount of the concentration of $\mathrm{H}_{2} \mathrm{O}_{2}$ and $\mathrm{Fe}^{2+}$ was increased. At the

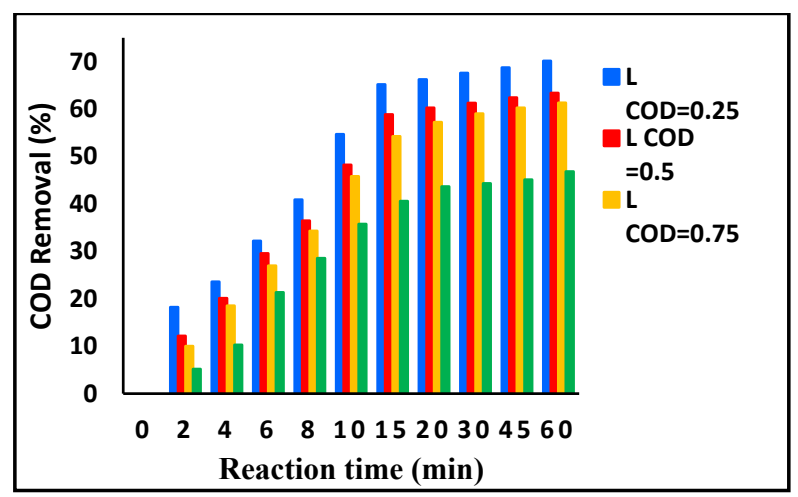

Fig . 8: Correlation between the COD removal of $1.0 \times 10^{-4} \mathrm{M} \mathrm{DB} 2\left(\mathrm{COD}=224 \mathrm{mg} \mathrm{O} \mathrm{O}_{2} \mathrm{~L}^{-1}\right)$ versus reaction time. Experimental conditions: $\mathrm{pH}=3.5$ and molar ratio $\mathrm{H}_{2} \mathrm{O}_{2} / \mathrm{Fe}^{2+}=11$.

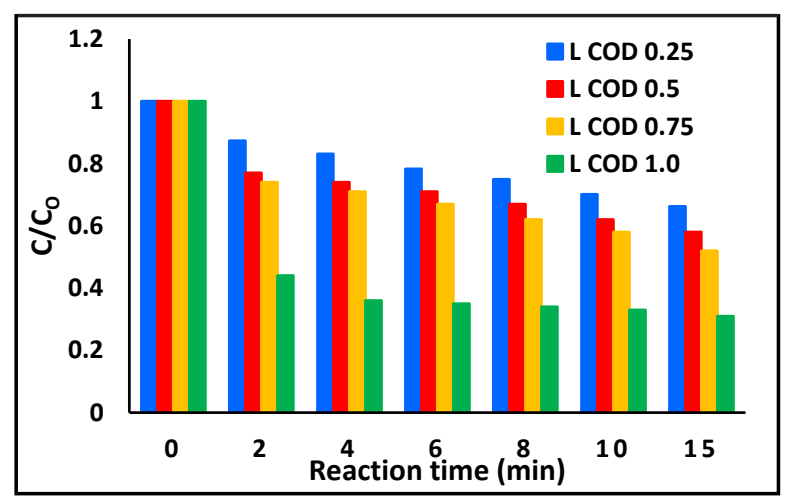

Fig. 9: The consumption of $\mathrm{H}_{2} \mathrm{O}_{2}$ using different. $L_{\mathrm{COD} \text { factor }}$ Experimental conditions $[\mathrm{DB} 2]=1.0 \times 10^{-4} \mathrm{M} \mathrm{pH}=3.5$. 
maximum $\left(L_{\mathrm{COD}}=1.0\right) 41 \%$ of $\mathrm{COD}$ was removed at 15 min while at the minimum $\left(L_{\mathrm{COD}}=0.25\right) 65 \%$ of COD was removed at the same time. These results approved that there was a residual amount of $\mathrm{H}_{2} \mathrm{O}_{2}$ in solution after 15 min of Fenton's oxidation reaction (Fig. 9). Although, all the $\mathrm{Fe}^{2+}$ was transformed to $\mathrm{Fe}^{3+}$, and that may decrease the reaction rate of $\mathrm{Fe}^{2+}$ with $\mathrm{H}_{2} \mathrm{O}_{2}$, low amount of $\mathrm{H}_{2} \mathrm{O}_{2}$ was consumed (Fig. 9). The results of consuming the $\mathrm{H}_{2} \mathrm{O}_{2}$ showed that the $82 \% \mathrm{H}_{2} \mathrm{O}_{2}$ was consumed after $15 \mathrm{~min}$ at $L_{\mathrm{COD}}=1.0$ while only about $43 \% \mathrm{H}_{2} \mathrm{O}_{2}$ was consumed at $L_{\mathrm{COD}}=0.25$.

\section{Effect of DB 2 Concentration on Colour Removal Kinetics}

The colour removal efficiency at different concentrations of DB 2 was studied. The result was observed that the decolourization of dye increases with the decrease of primary DB 2 concentration (Fig. 10). As the concentration of dye decreased from $1.5 \times 10^{-4} \mathrm{M}$ to $5.0 \times 10^{-5} \mathrm{M}$, the decolourization efficiency of dye increased from $43 \%$ to $93 \%$ within the first 10 min of reaction. A decrease in the concentration of DB 2 dye reveals that lesser dye molecules will be available to scavenging by $\mathrm{HO}^{\circ}$ radicals which lead to an increase in the colour removal efficiency of DB 2 (Javaid \& Qazi 2019) . Table 5 represents the second-order kinetic rates of colour removal of DB 2 at various DB 2 concentrations. Also, Table
5 shows the effect of different $\left[\mathrm{H}_{2} \mathrm{O}_{2}\right] /[\mathrm{DB} 2]$ ratios with an increase of colour removal kinetics combined with fact that the colour removal kinetics inversely proportional with DB 2 concentration in two varied steps.

A tenuous increase in colour removal kinetic rate (from 407 to $2604 \mathrm{M}^{-1} \mathrm{~min}^{-1}$ ) occurred when the ratio $\mathrm{H}_{2} \mathrm{O}_{2}$ /dye increases from 7.3 to 11 . However, increasing the $\mathrm{H}_{2} \mathrm{O}_{2}$ /dye ratio from 11 to 22 , there was an acute increase in colour removal kinetic rate (from 2604 to $23415 \mathrm{M}^{-1} \mathrm{~min}^{-1}$ ). Furthermore, the efficiency of DB2 colour removal increases with decreasing $\mathrm{H}_{2} \mathrm{O}_{2} / \mathrm{DB} 2$ molar ratio, which points out that a higher concentration of DB 2 was removed by using a smaller dose of $\mathrm{H}_{2} \mathrm{O}_{2}$ (Fig. 10).

\section{The Influence of Inorganic Ions on DB 2 Colour Removal by Fenton Oxidation}

The influence of some inorganic anions on the colour removal of DB 2 was tested at the optimum conditions. The experiments were designed to decompose $\left(1.0 \times 10^{-4} \mathrm{M}\right) \mathrm{DB} 2$ in the presence of $1.0 \%$ of inorganic salt used in this study.

Due to the expectation of the existence of a large number of anions in industrial textile wastewater, consequently, we intend to assess the decolourization of DB 2 in high doses of selected inorganic salts. The existence of inorganic anions

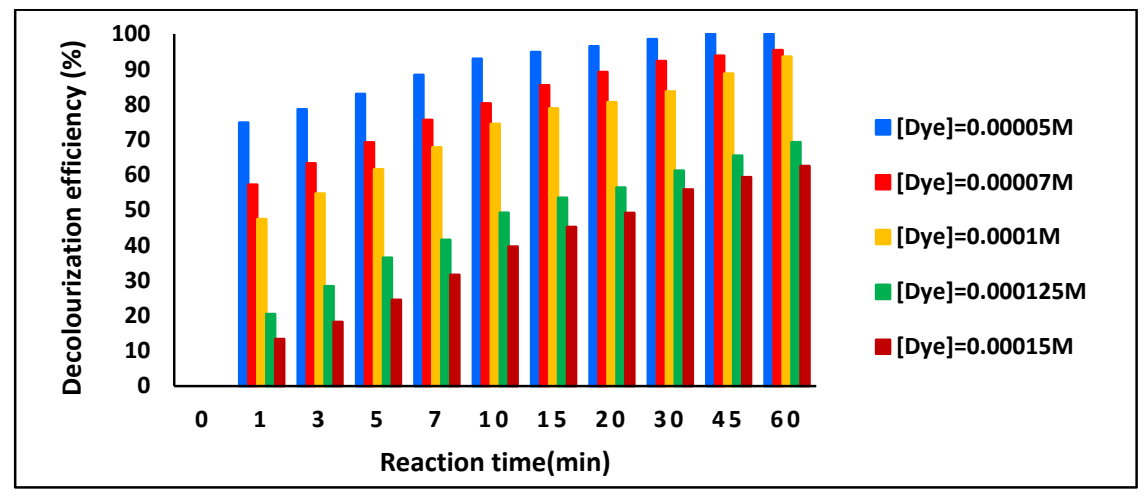

Fig. 10: Effect of initial DB 2 concentration on its colour removal efficiency during Fenton oxidation. Experimental conditions: $\left[\mathrm{H}_{2} \mathrm{O}_{2}\right]=1.1 \times 10^{-3} \mathrm{M}$, $\left[\mathrm{Fe}^{2+}\right]=1.0 \times 10^{-4} \mathrm{M}$ and $\mathrm{pH}=3.5$.

Table 5: Second-order kinetic constants and regression coefficients for each DB 2 concentration during Fenton oxidation Experimental conditions: [Fe ${ }^{2+}$ ] $=1.0 \times 10^{-4} \mathrm{M},\left[\mathrm{H}_{2} \mathrm{O}_{2}\right]=1.1 \times 10^{-3} \mathrm{M}$ and $\mathrm{pH}=3.5$.

\begin{tabular}{|llll|}
\hline$[\mathrm{DB} 2](\mathrm{M})$ & {$\left[\mathrm{H}_{2} \mathrm{O}_{2}\right] /[\mathrm{DB} 2]$} & $\mathrm{K}_{2}\left(\mathrm{M}^{-1} \mathrm{~min}^{-1}\right)$ & $\mathrm{R}^{2}$ \\
\hline $1.5 \times 10^{-4}$ & 7.3 & 407 & 0.9819 \\
$1.25 \times 10^{-4}$ & 8.8 & 716 & 0.9714 \\
$1.0 \times 10^{-4}$ & 11 & 2604 & 0.9567 \\
$7.0 \times 10^{-5}$ & 15.7 & 7326 & 0.9501 \\
$5.0 \times 10^{-5}$ & 22 & 23415 & 0.94 \\
\hline
\end{tabular}




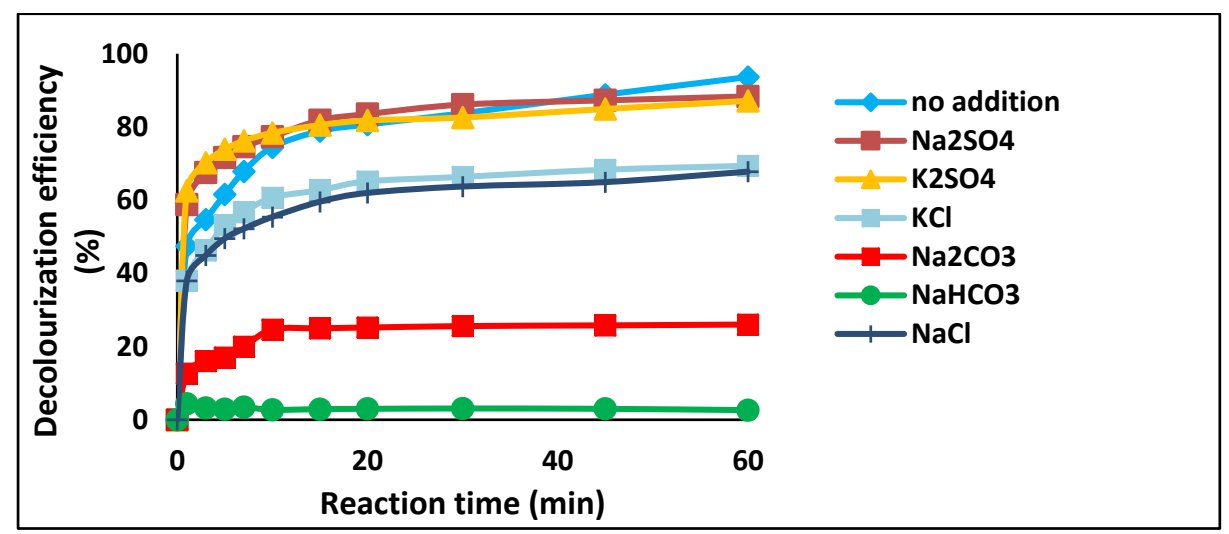

Fig: 11: Effect of addition of $1.0 \%$ inorganic anionic on DB 2 colour removal efficiency. Experimental conditions: $\mathrm{pH}=3.5$, $[\mathrm{DB} 2]=1.0 \times 10^{-4} \mathrm{M}$, $\left[\mathrm{H}_{2} \mathrm{O}_{2}\right]=1.1 \times 10^{-3} \mathrm{M}$ and $\left[\mathrm{Fe}^{2+}\right]=1.0 \times 10^{-4} \mathrm{M}$.

in the aqueous solution had a high effect on Fenton oxidation (Oliveira et al. 2015). In this research, the influence of carbonate, bicarbonate, sulphate and chloride on the Fenton process was evaluated. Fig. 11 shows the effect of the studied anions on the DB 2 degradation by Fenton oxidation process. Anions inhibit the degradation of DB 2 in the following order: $\mathrm{HCO}_{3}{ }^{-}>\mathrm{CO}_{3}{ }^{2-}>\mathrm{Cl}^{-}>\mathrm{SO}_{4}{ }^{2-}$

The addition of inorganic salts displayed various suppressed behaviours in Fenton process treatment. The influence of the addition of $\mathrm{HCO}_{3}{ }^{-}$and $\mathrm{CO}_{3}{ }^{2-}$ may be attributed to a decrease in the average of production of $\mathrm{HO}^{\circ}$ because of the formation of $\mathrm{CO}_{3}{ }^{-}$as shown in Eqs. (10) and (11).

$$
\begin{gathered}
\mathrm{HO}^{\circ}+\mathrm{HCO}_{3}{ }^{-} \rightarrow \mathrm{H}_{2} \mathrm{O}+\mathrm{CO}_{3}{ }^{--} \\
\mathrm{HO}^{\circ}+\mathrm{CO}_{3}{ }^{2-} \rightarrow \mathrm{OH}^{-}+\mathrm{CO}_{3}{ }^{--}
\end{gathered}
$$

The radical $\mathrm{CO}_{3}{ }^{\circ}$ is less reactive than $\mathrm{HO}^{\circ}$ radicals. In the case of $\mathrm{Cl}^{-}$, it also has a great effect on the decomposition of DB 2 because it reacts with $\mathrm{Fe}^{2+}$ forming complex and free radical less effective than the radical of hydroxyl as shown in Eqs. (12) and (13).

$$
\begin{aligned}
& \mathrm{Fe}^{2+}+\mathrm{Cl}^{-} \rightarrow \mathrm{FeCl}^{+} \\
& \mathrm{Cl}^{-}+\mathrm{HO}^{-} \rightarrow \mathrm{ClOH}^{\circ-}
\end{aligned}
$$

The salts of the sulphate ion appear to have less effect on the Fenton process, where sulphate ion reacts with $\mathrm{Fe}^{2+}$ and $\mathrm{HO}^{\circ}$, a component $\mathrm{HO}^{\circ}$ [Eqs. (14) and (15)] (Kehinde and Abdul Aziz 2014).

$$
\begin{gathered}
\mathrm{Fe}^{2+}+\mathrm{SO}_{4}{ }^{2-} \rightarrow \mathrm{FeSO}_{4} \\
\mathrm{HSO}_{4}+\mathrm{HO}^{*} \rightarrow \mathrm{SO}_{4}{ }^{--}+\mathrm{H}_{2} \mathrm{O}
\end{gathered}
$$

\section{CONCLUSIONS}

The parameters for loading azo bond factor $\left(L_{\text {azo bond }}\right)$ or COD loading factor $\left(L_{\mathrm{COD}}\right)$ were highly effective parameters of colour removal (decolourization) efficiencies using the batch system by Fenton oxidation. The results obeyed that the overdosed $\mathrm{H}_{2} \mathrm{O}_{2}$ was scavenging hydroxyl free radicals. The influence of the addition of $\mathrm{HCO}_{3}{ }^{-}$and $\mathrm{CO}_{3}{ }^{2-}$ may be attributed to a decrease in the average of production of $\mathrm{HO}^{\circ}$ because of the formation of $\mathrm{CO}_{3}{ }^{-}$. The radical $\mathrm{CO}_{3}{ }^{-}$is less reactive than $\mathrm{HO}^{\circ}$ radicals and the salts of the sulphate ion appear to have less effect on the Fenton process.

\section{REFERENCES}

Agustina, T. E. and Ang, H. M. 2012. Decolourization and mineralization of C.I. reactive blue 4 and C.I. reactive red 2 by Fenton oxidation process. International Journal of Chemical and Environmental Engineering, 3(3): 142-148.

Dehghani, M., Mosleheyan, M., Karimiyan, S., Faramarzi, Z., Ansari, M., Shamsedini, N., Reza Javaheri, M. and Shahsavani, S. 2016. Efficiency of the photo Fenton process for Decolourization of direct red 81 dye from the aqueous solution. Jundishapur J. Health Sci., 8(4): e34951.

Dewil, R., Mantzavinos, D., Poulios, I. and Rodrigo, M. A. 2017. New perspectives for advanced oxidation processes. Journal of Environmental Management, 195: 93-99.

Esteves, B. M., Rodrigues, C. S., Boaventura, R. A., Maldonado-Hodar, F. J. and Madeira, L. M. 2016. Coupling of acrylic dyeing wastewater treatment by heterogeneous Fenton oxidation in a continuous stirred tank reactor with biological degradation in a sequential batch reactor. J. Environ. Manage., 166: 193-203.

Garcia-Segura, S. and E. Brillas. 2016. Combustion of textile monoazo, diazo and triazo dyes by solar photoelectro-Fenton: Decolorization, kinetics and degradation routes. Applied Catalysis B: Environmental, 181: 681-691.

Holkar, C. R., Jadhav, A. J., Pinjari, D. V., Mahamuni, N. M. and Pandit, A. B. 2016. A critical review on textile wastewater treatments: Possible approaches. Journal of Environmental Management, 182: 351-366.

Javaid, R. and U.Y. Qazi. 2019. Catalytic oxidation process for the degradation of synthetic dyes: An overview. International Journal of Environmental Research and Public Health, 16: 2066.

Jin, H., Tian, X., Nie, Y., Zhou, Z., Yang, C., Li, Y. and Lu, L. 2017. Oxygen vacancy promoted heterogeneous Fenton-like degradation of ofloxacin at pH 3.2-9.0 by Cu substituted magnetic Fe3O4@FeOOH nanocomposite. Environ. Sci. Technol., 51(21): 12699-12706.

Kehinde, F. and Abdul Aziz, H. 2014. Textile wastewater and the advanced oxidative treatment process, an overview. International Journal of Innovative Research in Science, Engineering and Technology, 3(8): 15310-15316. 
Liu, Y., Jin, W., Zhao, Y., Zhang, G. and Zhang, W. 2017. Enhanced catalytic degradation of methylene blue by -Fe2O3/graphene oxide via heterogeneous photo-Fenton reactions. Applied Catalysis B: Environmental, 206: 642-652.

Lopez-Alvarez, B., Torres-Palma, R. A., Ferraro, F. and Penuela, G. 2012. Solar photo-Fenton treatment of carbofuran: analysis of mineralization, toxicity, and organic by-products. J. Environ. Sci. Health A Tox. Hazard. Subst. Environ. Eng., 47(13): 2141-50.

Lucas, M. S. and Peres, J. A. 2006. Decolourization of the azo dye reactive black 5 by Fenton and photo-Fenton oxidation. Dyes and Pigments, 71(3): 236-244.

Luo, L., Yao, Y., Gong, F., Huang, Z., Lu, W., Chen, W. and Zhang, L. 2016. Drastic enhancement on Fenton oxidation of organic contaminants by accelerating $\mathrm{Fe}(\mathrm{iii}) / \mathrm{Fe}$ (ii) cycle with 1-cysteine. RSC Advances, 6(53): 47661-47668.

Mousset, E., Oturan, N., van Hullebusch, E. D., Guibaud, G., Esposito, G. and Oturan, M. A. 2014. Treatment of synthetic soil washing solutions containing phenanthrene and cyclodextrin by electro-oxidation. Influence of anode materials on toxicity removal and biodegradability enhancement. Applied Catalysis B: Environmental, 160-161: 666-675.

Nidheesh, P. V., Gandhimathi, R. and Ramesh, S. T. 2013. Degradation of dyes from aqueous solution by Fenton processes: A review. Environmental Science and Pollution Research, 20(4): 2099-2132.

Nogueira, R. F. P., Oliveira, M. C. and Paterlini, W. C. 2005. Simple and fast spectrophotometric determination of $\mathrm{H} 2 \mathrm{O} 2$ in photo-Fenton reactions using metavanadate. Talanta, 66(1): 86-91.

O'Dell, J. W. 1939. Determination of Chemical Oxygen Demand by Semi-Automated Colorimetry, U.S. Environmental Protection Agency.

Oliveira, T. D. D., Martini, W. S., Santos, M. D. R., Matos, M. A. C. and Rocha, L. L. D. 2015. Caffeine oxidation in water by Fenton and Fenton-like processes: Effects of inorganic anions and ecotoxicological evaluation on aquatic organisms. Journal of the Brazilian Chemical Society, 26: 178-184.

Orhon, D. and E. U. Çokgör. 1997. COD Fractionation in Wastewater Characterization-The State of the Art. Journal of Chemical Technology \& Biotechnology 68:283-293.

Razzak, N. R. B. and Hossain, D. 2016. Characterization and advanced oxidation treatment of dyeing effluent by Fenton's reagent. Water Resources, 43(3): 559-564.

Sharma, A., Ahmad, J. and Flora, S. J. S. 2018. Application of advanced oxidation processes and toxicity assessment of transformation products. Environmental Research, 167: 223-233.

Trovó, A. G., Hassan, A. K., Sillanpää, M. and Tang, W. Z. 2016. Degradation of acid blue 161 by Fenton and photo-Fenton processes. International Journal of Environmental Science and Technology, 13(1): 147-158.

Wu, T. and Englehardt, J. D. 2012. A new method for removal of hydrogen peroxide interference in the analysis of chemical oxygen demand. Environmental Science \& Technology, 46(4): 2291-2298. 